\title{
DIETARY INTAKE OF ORGANOCHLORINE PESTICIDES THROUGH FISH FROM BULGARIAN BLACK SEA COAST
}

\author{
S. Georgieva*, M. Stancheva \\ Department of Chemistry, Medical University - Varna, Varna, Bulgaria
}

\begin{abstract}
PURPOSE: The objective of this study was to estimate the dietary intake (EDI) of organochlorine pesticides (DDT and its metabolite) through consumption of fish in Bulgaria. The potential health risk was assessed based on the dietary intake of DDTs through fish consumption.

METHODS: DDT and its two main metabolites DDE and DDD were determined in muscle tissue of six fish species widely consumed by the population of Bulgaria: goby (Neogobius melanostomus), sprat (Sprattus sprattus), grey mullet (Mugil cephalus), horse mackerel (Trachurus Mediterraneus ponticus), shad (Alosa pontica pontica) and bluefish (Pomatomus saltatrix). Samples were collected from Black Sea coast of Bulgaria during 2007 - 2011. The DDT and its metabolites were determined by capillary gas chromatography system with mass spectrometry detection.

RESULTS: The levels of the Total DDTs (sum of DDT, DDE and DDD) ranged from $18.5 \pm 8.3$ to $200.2 \pm 41.9 \mathrm{ng} / \mathrm{g}$ wet weight (in goby and shad, respectively). The mean EDI of DDTs in fish from Black Sea was calculated between $3.5 \pm 1.6$ and $37.8 \pm 7.9 \mathrm{ng} / \mathrm{kg}$ body weight/ day through consumption of goby and shad, respectively. The health risk was assessed using a risk quotient (RQ) of the fish consumption as the ratio of daily fish exposure level (EDI) in relation to oral reference dose.

CONCLUSIONS: The estimated dietary intake of DDTs through marine fish for the Bulgarian consumer does not pose a health risk.
\end{abstract}

Key words: DDTs; risk quotient; Black Sea; Bulgaria

\section{INTRODUCTION}

Organochlorine compound 1,1,1-trichloro - 2,2 - bis (4-chlorophenyl) ethane (DDT) and its metabolites were listed as persistent organic pollutants (POPs) in the Stockholm Convention (1). These chemicals are lipophilic, persistent, and rapidly accumulated in living organism and through the food chain (2). DDT was the first widely used synthetic pesticide (3). Intensive agricultural use of organochlorine pesticides in the past, have led to widespread contamination of the environment. These persistent compounds are transported by air all over the world, because they are driven by temperature and their volatility (4). In the environment DDT metabolizes slowly and the key metabolite DDE (1-1 dichloro-2,2-bis (p-chlorophenyl) ethylene) is also persistent compound (5). DDT is still used for vector control against malaria (6). These very persistent compounds

\footnotetext{
*Correspondence to: Stanislava Katelieva Georgieva, Tel.:+ 35952677 050, Fax:+ 35952 650 019, Marin Drinov 55, 9002, Varna, E-mail: stanislavavn@mail.bg
}

have the potential to affect the physiological functions of wildlife (7). Marine organisms such as fish and marine filter feeders, can also act as bioconcentrators, creating levels of DDT in their tissues above ambient environmental concentrations (3). The use of DDT was banned in most developed countries after 1970 as a result of these environmental concerns. Even today DDT remains so widespread in the environment that it is likely that exposure to it is unavoidable (3).

Many authors have revealed that high fish and seafood consumption increases the risk of DDTs contamination of the human body $(1,8$, 9). Humans are exposed inadvertently to POPs through numerous sources, of which the consumption of contaminated fish is one of the most important pathways (10). Dietary intake is an important route of human exposure to organochlorine compounds $(11,12)$. Several studies have investigated the dietary exposure and assessed the risk of POPs for the general population through the consumption of food in various countries $(11,13,14,15)$. Therefore, risk assessment of the POPs in seafood is 
important and necessary to manage risks from seafood intake $(16,17)$. Current non-cancer risk assessment methods are usually based on the use of the Risk quotient (RQ). RQ is a ratio between the estimated dose of a contaminant and the reference dose below which there will not be any appreciable risk (18). If RQ exceeds unity, there may be concern for potential health effects.

The objectives of this study were to estimate the dietary intake (EDI) of DDT and its metabolite through consumption of fish in Bulgaria and to assess the human health risk.

\section{MATERIALS AND METHODS}

\section{Sampling}

Samples were caught by local professional fishermen by net from 2007 to 2011. The fish species were selected according to their importance to human consumption in Bulgaria: goby (Neogobius melanostomus), sprat (Sprattus sprattus), grey mullet (Mugil cephalus), horse mackerel (Trachurus Mediterraneus ponticus), shad (Alosa pontica pontica) and bluefish (Pomatomus saltatrix).

\section{Analytical method}

Samples were prepared according to a previously described method for the preparation and quantitative determinations of DDTs in fish (19). Briefly, twenty grams of homogenized fish tissue were extracted with hexane / dichloromethane in Soxhlet Extractor. The extract was cleaned-up on a glass column packed with $2 \mathrm{~g}$ neutral silica, $4 \mathrm{~g}$ acid silica and $2 \mathrm{~g}$ neutral silica (Merck KGaA, Darmstadt, Germany). The eluates were concentrated to near dryness and reconstituted in $0.5 \mathrm{ml}$ in hexane. One micro liter of purified extract was injected into GC/MS.

An aliquot of the extract (1/5th) was taken for lipid determination. The solvent was carefully evaporated until dryness and the lipid content was determined gravimetrically.

After lipid determination, the extract was cleaned-up on a glass column packed with neutral and acid silica. Organochlorine compound were eluted with $50 \mathrm{ml}$-hexane followed by $50 \mathrm{~cm}^{3} \mathrm{n}$-hexane/ dichloromethane $(80: 20 \mathrm{v} / \mathrm{v})$. The eluates were concentrated to near dryness and reconstituted in $0.5 \mathrm{~cm}^{3}$ in hexane.

The simultaneous analysis was performed on gas chromatograph GC FOCUS (Thermo Electron Corporation, USA) using POLARIS Q Ion Trap mass spectrometer and equipped with an AI 3000 autosampler. Experimental masspectrometry parameters are: the Ion source and Transfer line temperatures were $220^{\circ} \mathrm{C}$ and $250^{\circ} \mathrm{C}$, respectively. The splitless Injector temperature was $250^{\circ} \mathrm{C}$. For DDTs determination the oven was programmed as follows: $50^{\circ} \mathrm{C}(1 \mathrm{~min}), 30^{\circ} \mathrm{C} / \mathrm{min}$ to $180^{\circ} \mathrm{C}$, $5^{\circ} \mathrm{C} / \mathrm{min}$ to $260^{\circ} \mathrm{C}, 30^{\circ} \mathrm{C} / \mathrm{min}$ to $290^{\circ} \mathrm{C}$ with a final hold for $3.0 \mathrm{~min}$. Helium was applied as carrier gas at a flow of $1 \mathrm{ml} / \mathrm{min}$.

Pure reference standard solutions (EPA 625/CLP Pesticides Mix $2000 \mu \mathrm{g} / \mathrm{ml}$ Supelco) were used for instrument calibration, recovery determination and quantification of compounds. In prepared extracts 1,1-dichloro2,2-di(4-chlorophenyl) ethylene (p,p'-DDE), 1,1-dichloro-2,2-di(4-chlorophenyl)ethane (p,p'-DDD) and 1,1,1-trichloro-2,2-di(4chlorophenyl)ethane (p,p'-DDT) were analyzed. Each sample was analyzed three times and was taken an average of the results obtained. The limits of detection (LOD) varied for individual compounds from 0.02 to 0.05 ng/g ww.

\section{Quality control}

The quality control was performed by regular analysis of procedural blanks and certified reference material BCR - 598 (DDTs in Cod liver oil) - Institute for Reference Materials and Measurements, European Commission. Recovery of DDTs from certified reference material varied in the range $85-109 \%$ for individual compounds.

\section{Statistical analysis}

The statistical analysis of the data was based on the comparison of average values by a t-test and a significance level of $p<0.05$ was used. All statistical tests were performed using SPSS 16 software.

\section{RESULTS}

\section{Dietary intake estimation}

Human exposure assessment of DDTs through oral ingestion is generally estimated using daily intake of the contaminant. The estimated total daily intake (EDI) of the contaminants in a given fish species was calculated as follow (13):

\section{$\mathrm{EDI}=\mathrm{C} \mathrm{x}$ Intake $/ \mathrm{BW}$}

where EDI is the estimated daily intake (ng/kg body wt./day), $\mathrm{C}$ is the mean concentration of measured DDTs in fish species (ng/g wet weight), Intake is the daily food consumption of fish (13.2 g/ day for Bulgarian standard adult, taking into consideration the Bulgarian national average diet (20) and BW is the average consumer body weight (70 kg for adult men). 
The concentration levels of DDTs compounds were described in detail in our previous study (19). The Total DDTs load of each fish species was calculated on the basis of the sum of DDE, DDD and DDT, ng/g wet weight (ww).
Mean values of the EDI (ng/kg bw/day) calculated for the DDT and its metabolite found in marine fish, collected during 20072011, are shown on Figure 1.

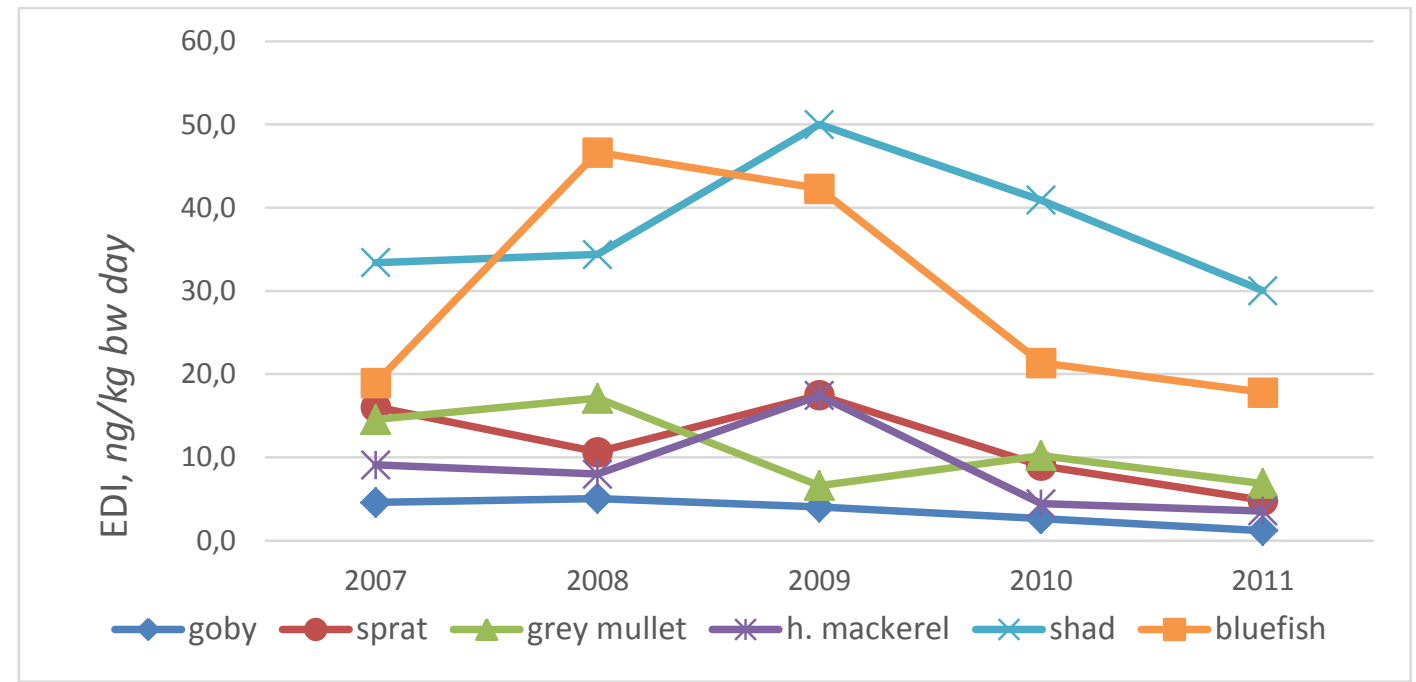

Figure 1. Values of the EDI (ng/kg bw/day) assessed for the DDTs found in marine fish, collected during 2007-2011

\section{Human health risk assessment}

The potential risks of non-carcinogenic effects are evaluated by the risk assessment index known as the risk quotient (RQ). RQ is defined as the ratio of daily fish exposure level (EDI) in relation to reference dose (RfD) considering non-carcinogenic effects of the contaminants. The RQ was calculated as follows $(13,18)$ :

$\mathrm{RQ}=\mathrm{EDI} / \mathrm{RfD}$

where EDI is the estimated daily intake (ng/kg body weight/day); and RfD is the Chronic reference dose (ng/kg day). The RfD applied in this study was $500 \mathrm{ng} / \mathrm{kg}$ day (18).

The lipid contents of each fish species, mean levels of Total DDTs (average of study period 2007-2011) in investigated fish species from the Black Sea coast of Bulgaria, mean estimated daily intake (average of EDI during 2007-2011) and risk quotient (RQ) are shown in Table 1. The lipid percentage ranged from $1.7 \%$ in goby to $22.6 \%$ in shad.

Table 1. The lipid contents (\%), mean levels of Total DDTs, $n g / g$ wet weight (2007-2011) determined in fish collected from the Black Sea, Estimated daily intake (EDI), $\mathrm{ng} / \mathrm{kg}$ bw day and Risk quotient $(R Q), n g / k g b w / d a y$

\begin{tabular}{lcccccc}
\hline Species & $\mathrm{n}$ & Lipids & $\begin{array}{c}\text { DDTs } \\
(2007-2011)\end{array}$ & EDI & $\begin{array}{c}\text { RfD } \\
\text { (USEPA) }\end{array}$ & RQ \\
\hline goby & 18 & $1.7 \pm 0.6$ & $18.5 \pm 8.3$ & $3.5 \pm 1.6$ & & 0.007 \\
sprat & 11 & $5.8 \pm 1.8$ & $61.5 \pm 27.5$ & $11.6 \pm 5.2$ & & 0.023 \\
grey mullet & 12 & $8.3 \pm 2.8$ & $58.7 \pm 24.7$ & $11.1 \pm 4.7$ & $\mathbf{5 0 0}$ & 0.022 \\
horse mackerel & 18 & $11.7 \pm 2.6$ & $45.1 \pm 29.2$ & $8.5 \pm 5.5$ & & 0.017 \\
shad & 12 & $22.6 \pm 6.2$ & $200.2 \pm 41.9$ & $37.8 \pm 7.9$ & & 0.076 \\
bluefish & 11 & $18.6 \pm 4.1$ & $156.0 \pm 73.7$ & $29.4 \pm 13.9$ & & 0.059 \\
\hline
\end{tabular}

\section{DISCUSSION}

Estimated daily intake (EDI) of DDTs

It has been proven that fish and seafood are one of the major routes of human exposure to organic contaminants (21). The consumption of contaminated fat food can be a potential risk for the consumer. To evaluate risk exposure, the mean EDIs for these harmful chemicals in each fish species were calculated. On the basis of the measured concentrations in the fish samples (19), the daily dietary intake of DDTs was calculated. The estimated daily intake of the DDTs through fish species studied in the period 2007 - 2011 is shown in Figure 1. The 
estimated daily intake was calculated on the basis of a fish consumption rate of $13.2 \mathrm{~g} /$ day (20) for adults with body weight of $70 \mathrm{~kg}$, on the mean exposure level.

The dietary intake of DDTs for the Bulgarian adult was estimated in the range from 1.2 $\mathrm{ng} / \mathrm{kg}$ bw day (goby 2011) to $50.0 \mathrm{ng} / \mathrm{kg}$ bw day (shad 2009). Some species showed high contributions compared with the other species. Shad had the highest contribution of DDTs compounds. The statistical analysis indicated that the differences among mean annual estimated EDI of DDTs were not statistically significant within a species ( $>0.05)$. Evaluated daily intakes decrease slowly during the period of study $(2007-2011)$ in all fish species - Figure 1.

The differences in feeding preferences and lipid content of different fish species justify the large range of EDIs (from 3.5 to $37.8 \mathrm{ng} / \mathrm{kg}$ bw/ day, in goby and shad, respectively). The statistical test indicated that the mean EDIs calculated in shad were significantly higher than those in goby $(p<0.05)$. It can be seen (Table 1) that the fish with a higher lipid content had high contributions for DDTs (such as shad and bluefish) while those with a low fat content (goby, sprat, grey mullet) had low contributions of organochlorines compound.

A comparison of the dietary intakes of DDTs compounds from fish in Bulgaria with published data shows that the dietary intakes of DDTs in Sweden - $256 \mathrm{ng} /$ day (22), in Italy $197 \mathrm{ng} /$ person day (14) and in South Korea $270 \mathrm{ng} /$ day (11) were higher than those in the present study.

The fish species are a common element in the diet of most individuals; they represent a major exposure route for persistent compounds from the aquatic systems into humans $(9,24)$. EU legislation did not set a maximum residue level (MRL) for DDTs in fish, but only in meat and preparations of meat. The mean EDI levels found in fish species in this study were compared to the minimum risk levels (MRLs) - $500 \mathrm{ng} / \mathrm{kg} /$ day for oral intake of these compounds (23). MRL (ng/day) for a person of $70 \mathrm{~kg}$ was calculated $35000 \mathrm{ng} /$ day (9). To exceed the MRL for DDTs, a mean adult Bulgarian consumer must eat more than $389 \mathrm{~g}$ of marine fish every day.

\section{Human health risk assessment}

For chronic systemic toxicants, the RfD is used as a reference point in assessing risk (24). The RfD is an estimate, with an uncertainty of perhaps an order of magnitude, of a daily exposure that is likely to be without appreciable risk of deleterious health effects in the human population (including sensitive subgroups) over a lifetime $(13,18)$.

The average consumption together with the measured concentration of the contaminant is used to calculate the risk quotient RQ - Table 1. RfD values adopted in this study are the criteria of the USEPA (Environment Agency of the United States) - Chronic reference dose (18). RQ less than unity indicates that the chemical involved is less likely to pose a significant health risk to the consumers. RQ greater than unity would indicate that exposure concentration exceeds RfD and a more refined risk assessment is needed to ascertain whether appropriate control or management measures are required $(13,25)$. The likelihood of risk is related to the degree to which exposure exceeds the RfD. Risk also depends on individual characteristics; susceptibility to toxic exposures varies considerably in most populations. Consequently, the primary use of RfDs is to provide a protective exposure limit rather than to predict risks. In practice, however, they are often used to estimate risk (18).

The RQ values ranged from 0.007 to 0.076 for goby and shad, respectively (Table 1). It can be seen that the fish with a lower lipid content had a lower RQ (goby, sprat, grey mullet) while those with a high fat content such as shad and bluefish, had a higher RQ. In our study all the RQ values were much lower than 1 , suggesting that consumption of the fish species from Black Sea Bulgaria, would not pose a non-cancer risk.

\section{CONCLUSION}

Dietary intake of DDTs compounds from fish in Bulgaria was estimated lower than those in the published data from other study. Evaluated daily intakes decrease slowly during the period of study $(2007-2011)$ in all fish species. The estimated intake levels of DDTs through consumption of fish from Black Sea, Bulgaria were several orders lower than their respective RfD for adults. The RQ values were much lower than unity, suggesting that consumption of the fish species would not pose a health risk for the adult Bulgarian consumer.

\section{REFERENCES}

1. UNEP Stockholm Convention on Persistent Organic Pollutants (POPs). Available from: http://www.chem.unep.ch/sc/. Stockholm Convention, 2001

2. Masmoudi, W., Romdhane, M.S., Kherriji, S., El Cafsi, M., Polychlorinated biphenyl 
residues in the golden grey mullet (Liza Aurata) from Tunis Bay, Mediterranean Sea (Tunisia). Food Chem, 105:72-76, 2007.

3. Beard, J., DDT and human health. Sci Total Environ, 355:78- 89, 2006.

4. Gouin, T., Harner, T., Daly, G.L., Wania, F., Mackay, D., Jones, K.C., Variability of concentrations of polybrominated diphenyl ethers and polychlorinated biphenyls in air: implications for monitoring, modeling and control. Atmosph Environ, 39:151-166, 2005.

5. Ferreira, M., Antunes, P., Gil, O., Vale, C., Reis-Henriques, M.A., Organochlorine contaminants in flounder (Platichthys flesus) and mullet (Mugil cephalus) from Douro estuary, and their use as sentinel species for environmental monitoring. Aquatic Toxicol, 69:347-357, 2004.

6. WHO, The use of DDT in malaria vector control, Global Malaria Programme. 2007, Available

from: http://www.who.int/malaria/publications/at oz/who_htm_gmp_2011/en/

7. Langer, P., Kocan, A., Tajtakova, M., Petrik, J., Chovancova, J., Drobna, B., et al. Possible effects of polychlorinated biphenyls and organochlorinated pesticides on the thyroid after long-term exposure to heavy environmental pollution. $J$ of Occup \& Environ Med, 45:526- 532, 2003.

8. Voorspoels, S., Covaci, A., Neels, H., Dietary PCB intake in Belgium, Environ Toxicol and Pharmacol, 25:179-182, 2008.

9. Van Ael, E., Covaci, A., Blust, R., Bervoets, L., Persistent organic pollutants in the Scheldt estuary: Environmental distribution and bioaccumulation, Environ Intern, 48:17-27, 2012.

10.UNEP, Human exposure to POPs across the globe: POPs levels and human health implications. 2013. Available from: http://www.unep.org/chemicalsandwaste/po rtals/9/POPs/docs/UNEP-POPS-COP.6INF-33.English.pdf

11.Moon, H.-B., Kim, H.-S., Choi, M., Yu, J., Choi, H.-G., Human health risk of polychlorinated biphenyls and organochlorine pesticides resulting from seafood consumption in South Korea, 2005-2007. Food and Chem Toxicol, 47:1819-1825, 2009.

12.Li, X., Gan, Y., Yang, X., Zhou, J., Dai, J., $\mathrm{Xu}, \quad \mathrm{M}$., Human health risk of organochlorine pesticides (OCPs) and polychlorinated biphenyls (PCBs) in edible fish from Huairou Reservoir and Gaobeidian Lake in Beijing, China. Food Chem, 109:348-354 2008.
13.Yu, Y., Wang, X., Yang, D., Lei, B., Zhang, X., Zhang, X., Evaluation of human health risks posed by carcinogenic and noncarcinogenic multiple contaminants associated with consumption of fish from Taihu Lake, China. Food and Chem Toxicol, 69:86-93, 2014.

14.Stefanelli, P., di Muccio, A., Ferrara, F., Barbini, D.A., Generali, T., Pelosi, P., Amendola, G., Vanni, F., Di Muccio, S., Ausili, A., Estimation of intake of organochlorine pesticides and chlorobiphenyls through edible fishes from the Italian Adriatic Sea during 1997. Food Control, 15:27-38, 2004.

15.Zhang, J., Feng, L., Chen, R., Feng, T., Dong, S. \& Shen, H., Levels of polychlorinated biphenyls and organochlorine pesticides in edible shellfish from Xiamen (China) and estimation of human dietary intake. Food and Chem Toxicol, 50:4285-4291, 2012.

16.Binelli, A., Provini, A., POPs in edible clams from different Italian and European markets and possible human health risk. Mar Poll Bull, 46:879-886, 2003.

17.Domingo, J.L., Bocio, A., Falcó, G., Llobet, J.M., Benefits and risks of fish consumption Part I. A quantitative analysis of the intake of omega-3 fatty acids and chemical contaminants. Toxicol, 230:219-226, 2007.

18.USEPA (United States Environmental Protection Agency). Guidance for Assessing Chemical Contaminant Data for Use in Fish Advisories. EPA 823-B-00-008, 2000;2, Available from: https://www.purdue.edu/hhs/nutr/fish4healt h/HealthRisks/EPAFCA200.pdf

19.Stancheva, M., Georgieva, S., Makedonski, L., Organochlorine Pollutants in Fish from the Bulgarian Region of the Black Sea. Qual Assur and Safety of Foods and Crops, 5(3):243 - 251, 2013.

20.NSI (National Statistical Institute), Republic of Bulgaria, Household income, expenditure and consumption during the first quarter of 2010, 2010: Available from: http://www.nsi.bg/EPDOCS/HBS20101q.pdf

21.Smith, A.G. \& Gangoli, S., Organochlorine chemicals in seafood: occurrence and health concerns. Food and Chem Toxicol, 40:76779, 2002.

22.Darnerud, P.O., Atuma, S., Aune, M., Bjerselius, R., Glynn, A., Grawé, K.P., Becker, W., Dietary intake estimations of organohalogen contaminants (dioxins, PCB, PBDE and chlorinated pesticides E.g. DDT) based on Swedish market basket data. Food Chem. Toxicol, 44:1597-1606, 2006. 
23.ATSDR, Agency for Toxic Substances and Disease Registry. Minimum risk levels (MRLs). 2010. Available from http://www.atsdr.cdc.gov/mrls/pdfs/atsdr_m rls_december_2010.pdf.

24.Dorea, J.G., Persistent, bioaccumulative and toxic substances in fish: human health considerations. Sci Total Environ, 400:93114, 2008.
25.So, M.K., Zhang, X., Giesy, J.P., Fung, C.N., Fong, H.W., Zheng, J., Kramer, M.J., Yoo, H., Lam, P.K.S., Organochlorines and dioxin-like compounds in green-lipped mussels Perna viridis from Hong Kong mariculture zones. Mar Poll Bull, 51:677687, 2005. 